\title{
perifèria
}

Número 7, Diciembre 2007

www.periferia.name

\section{Aspectos culturales de la elaboración de un postre tradicional, denominado panchón, en el municipio de Aller, Principado de Asturias, España}

Lastra Menéndez, J.J. \& J. Martínez González Universidad de Oviedo - Grupo de Investigación en Etnobotánica ${ }^{1}$

\section{Resumen}

Persiste en el municipio de Aller (Principado de Asturias) un postre tradicional realizado a base de harina de escanda (Triticum aestivum subsp. spelta). Su elaboración, aunque va transformándose con el tiempo, es muy peculiar, pues se hace en el hogar (lar, llar, tsar), cociéndose la masa protegida por unas capas aislantes de naturaleza vegetal, bajo brasas. Su forma tradicional de consumo es comunal, durante los días de fiesta patronales.

Palabras-Clave: etnobotánica, conocimiento tradicional, consumo.

\section{Abstract}

It persists in the municipality of Aller (Principality of Asturias) the elaboration of a traditional dessert made of spelt (Triticum aestivum subsp. spelta), their elaboration, although it goes transforming with the time, it is very peculiar, because it is made in the traditional stone cooker, cooking the very covered mass, low embers. Their traditional form of consumption is communal.

Keywords: ethnobotanics, traditional knowledge, consumption.

\section{I ntroducción}

\section{Área de Estudio}

Aller (Ayer) es un municipio predominantemente minero y ganadero, situado al sur de la Comunidad Autónoma "Principado de Asturias", en el norte de la Península Ibérica. La población ronda los 15.000 habitantes en el momento actual, presentando una dinámica de pérdida de población entre 200 y 300 habitantes al año, como consecuencia de la crisis de las cuencas mineras asturianas.

\footnotetext{
1 Enviar correspondencia a: jlastra@uniovi.es; xoxepu@uniovi.es. Grupo de Investigación en Etnobotánica. Departamento de Biología de Organismos y Sistemas. Universidad de Oviedo (Asturias). C/. Catedrático Rodrigo Uría, s/n. 33071 Oviedo- España
} 


\section{perifèria}

Número 7, Diciembre 2007

www.periferia.name

El medio físico se caracteriza por la pronunciada orografía, con una altitud media de 1.084 m.s.n.m. (metros sobre el nivel del mar), en un rango de altitudes que va desde los 350 hasta los 2.104 m.s.n.m. La pendiente media es acusada, del orden de un $29,1 \%$.

Posee un clima atlántico de montaña, con un máximo de precipitaciones en el mes de noviembre, y un mínimo en el de agosto, sin la existencia de un período seco. En cuanto a la temperatura es máxima en agosto y mínima en enero, siendo la temperatura media anual de $11,2^{\circ} \mathrm{C}$, y la precipitación media anual de $1.285,4$ litros $/ \mathrm{m}^{2}$.

Respecto a la litología, en el norte predominan los sustratos rocosos del Paleozoico, caracterizados por materiales de pizarra y carbón, acompañados de areniscas y conglomerados. El sur está constituido por enclaves de calizas carboníferas y calizas de montaña. Esta litología condiciona que los suelos sean fundamentalmente ácidos en el norte del concejo, y básicos en la zona sur.

En cuanto a su flora, estimamos la presencia de unos 900 taxa. La vegetación está constituida principalmente por prados de siega y pastos naturales; también destacan los matorrales de Erica sp., y Ulex sp., los bosques de hayas (Fagus sylvatica), abedules (Betula pubescens), acebos (Ilex aquifolium) y castaños (Castanea sativa).

Se denomina panchón a un postre elaborado con las migas de una pancha ${ }^{2}$ de harina de escanda, cocida de manera tradicional sobre unas piedras calizas calentadas con intensidad (hogar, lar, llar, tsar), mezcladas con manteca (mantega) y azúcar.

Características del panchón son sus modestos ingredientes: harina de escanda, manteca y azúcar; así como la forma de cocción de la pancha que da origen a las migas, sobre el lar, y no en el horno.

\footnotetext{
${ }^{2}$ Pancha. Pan redondo mal cocido.
} 


\section{perifèria}

Número 7, Diciembre 2007

www.periferia.name

\section{Cereales panificables en Asturias}

A lo largo de la historia de Asturias sus moradores han empleado seis cereales panificables. Tres de ellos de invierno: trigos (Triticum aestivum), centeno (Secale cereale) y las escandas ( $T$. turgidum subsp. dicoccum y T. aestivum subp. spelta); y tres cereales de verano: maíz (Zea mays), mijo (Panicum miliaceum) y panizo (Setaria italica). Todos ellos se encuentran adaptados a las diferentes condiciones climáticas y edáficas de la geografía asturiana, y cada uno ocupa un nicho ecológico propio, que sólo van a imbricarse en el caso de biotopos muy propicios.

En el municipio de Aller, debido a su clima atlántico, a la escasez de suelo fértil, y a las dificultades de laboreo, por lo abrupto del relieve, el cereal panificable más adecuado, fue y es la escanda.

\section{La escanda Asturiana}

La escanda (género Triticum) fue uno de los primeros cereales en ser recolectado por el hombre, junto con especies del género Aegilops, hace unos 20.000 años, y el primer cereal en ser cultivado ( $\approx 10.000$ años a.C.).

La escanda que se cultiva en Asturias corresponde a dos taxones: Triticum turgidum subsp. dicoccum y T. aestivum subsp. spelta. Las dos presentan las características propias de trigos rústicos, o si se quiere, primitivos, que se corresponden con caracteres fisiológicos y estructurales (Zohary, D. and M. Hopf, 2000: 18-19; Hancock, J.F., 2004: 191).

- Son trigos vestidos. Las cubiertas que rodean al grano, glumas, están pegadas a él, y es necesario para despegarlas un tipo de molino particular: el rabil o pisón.

- El ráquis o eje de sus espigas se disgrega con facilidad con el fin de posibilitar la dispersión de los frutos.

- Son cereales de invierno. Se siembran a fines de año ya que a sus plántulas les daña muy poco el frío.

- Las semillas prolongan su capacidad de germinación dos años, o más.

- Muestran un crecimiento superior al trigo común en condiciones adversas. Se caracterizan por poder crecer en suelos pobres, poco profundos, húmedos y fríos, y soportar los períodos invernales de lluvias intensas y de nevadas, en rangos de altitud entre 200 y $1.000 \mathrm{~m}$. 


\section{perifèria}

Número 7, Diciembre 2007

www.periferia.name

El T. turgidum subsp. dicoccum o povía, tiene confirmada su presencia en la Península Ibérica al final del Neolítico y comienzos de la Edad del Bronce (4.000 años A.C., Oliveira Prendes, J. A., 2001: 17). En Asturias aparecen restos de este trigo en distintos castros, en niveles prerromanos, concretamente en la Campa de Torres (Gijón), el Pico el Castiello de Morrión-Miravalles (Villaviciosa) y el Castiello de Camota (Villaviciosa) (García González de Lena, G., 2005: 29). Se considera que las tribus prerromanas conocían una agricultura de quema y roza que practicaban en espacios comunales de monte (Martínez Lorenzo, L., 1999: 375; González, J. M., 1975: 183-190). Sembraban cebada (Alvargonzález, C., 1908, 5; GonzálezQuevedo, R., 1995: 11 y sic.), y los hallazgos en restos arqueológicos permiten certificar que conocían la povía.

EI T. aestivum subsp. spelta, la escanda propiamente dicha, aparece en diversas zonas del norte de la Península Ibérica, a partir del año 1.000 A.C. (Oliveira Prendes, J. A., 2004-2005: 68). En Asturias, se confirma su presencia con la llegada de los romanos (García González de Lena, G., 2005: 28), y no es posible certificarla antes.

La romanización en Asturias fue más intensa de lo que se creía. Los romanos modificaron el medio rural y el espacio agrario. Poco a poco fueron imponiéndose una organización del territorio que aparece ya perfectamente perfilada en la baja edad media, y que duró hasta mediados y finales del $s$. XX. Los romanos introdujeron en el norte peninsular la propiedad de la tierra, avances en la agricultura, dos nuevos cereales panificables: la escanda, y el trigo común ( $T$. aestivum subsp. aestivum), la levadura, y el horno para cocer el pan, que hasta ese momento se elaboraba en un primitivo lar.

La escanda en el concejo de Aller se continuó sembrando desde la época romana hasta los años $80^{\prime}$ y $90^{\prime}$ del siglo pasado, aunque con algunas crisis a la finalización del s. XIX, como consecuencia de la especialización ganadera, del pago de las rentas en dinero y no en especias como hasta entonces se venía haciendo, y de la implantación definitiva del maíz como el principal cereal en la alimentación diaria. Las causas, últimas, más recientes, del abandono de su cultivo tienen que ver con la crisis del medio rural, la pérdida de puestos de trabajo estables, la emigración de 


\section{perifèria}

Número 7, Diciembre 2007

www.periferia.name

la juventud, el envejecimiento de la población y la fuerte competencia ejercida por la minería (Rodríguez Gutiérrez, F. 1998-1999: 61); si bien, esta última nunca ha sido una causa en si misma, pues los mineros asturianos también han sido y son, agricultores y ganaderos, quedando las mujeres al cargo de las caserías mientras los hombre iban a las minas (este es un aspecto de la realidad rural asturiana, perfectamente documentado, y en el que no vamos a entrar).

\section{La manteca (mantega)}

Este ingrediente fundamental del panchón, entraña una curiosa incongruencia: en una sociedad rural como la allerana, especializada en el ganado vacuno, la leche y sus derivados eran poco consumidos por los propios productores. Varias son las causas. La principal, económica. Los derivados de la leche, manteca y quesos, se vendían y constituía una de las pocas formas de ingresos en efectivo que tenía la familia. Otra, la poca producción de leche que daban las vacas porque, además, eran una ayuda imprescindible en las tareas del campo tirando de arados y carros, y criaban anualmente un ternero, también indispensable en la menguada economía de la casería.

Las mejores mantecas se obtenían en los meses de primavera, verano y parte del otoño, cuando las vacas estaban en los ricos pastizales de los puertos de montaña, brañas y mayeos, consecuencia de la trashumancia estacional característica de la zona.

Las mantecas de destinaban a la venta, y el vaquero y su familia consumía la leche desnatada, dibura.

\section{El azúcar}

Apenas se consumía en el Concejo de Aller hasta épocas recientes. La causa era la poca disponibilidad de este producto, y su alto precio. El principal edulcorante empleado era la miel.

No hay estudios acerca de la producción de miel en el concejo, al contrario de otras zonas de Asturias (López Álvarez, Xuacu, 1994). De nuestras notas de campo extraemos que la mayoría de las familias campesinas tenían unas pocas colmenas, 


\section{perifèria}

Número 7, Diciembre 2007

www.periferia.name

casietsos, para la obtención de miel y cera, estrictamente para autoconsumo. En Aller no se conoce la figura del colmenero o abeyero, que vive de la cría de las abejas. También tenemos noticias de la presencia de vendedores de miel procedentes de otras regiones, especialmente de La Alcarria (id.: 107).

\section{Metodología}

La metodología empleada está dentro del campo de la etnografía botánica o etnobotánica. Ciencia multidisciplinar que estudia la tradición y la innovación en los usos botánicos por parte de las sociedades humanas. Por usos botánicos entendemos todos los manejos que sobre la biota vegetal ha realizado, y realiza el hombre, utilizándola como recurso.

Todas las etnociencias comporten una parte metodológica común basada en métodos etnográficos. Se centran en la entrevista con informantes con el fin de recabar información; se obtienen así, los datos relativos a la temática específica de la ciencia sobre la que se realiza la investigación. Recurrimos, concretamente a la entrevista abierta, y a la semiestructurada, en las que se procura dar libertad temática, hasta cierto punto, al informante, con intervenciones puntuales del entrevistador, con el fin de encauzar y mantener la charla dentro de los temas de interés.

Debido a la flexibilidad inherente al método empleado, el investigador recopila un conjunto muy amplio de información, tenga que ver, o no, con el campo científico concreto de su interés. La información obtenida, se introduce en una base de datos relacional, con el fin de facilitar el acceso y el manejo de la misma.

La búsqueda de informantes se realizó en la fase inicial de la investigación al azar, para posteriormente entrevistar a aquellas personas, que dentro del conjunto de la población, están consideradas como conocedoras de las tradiciones populares y culturales.

De entre todas las entrevistas realizadas, seleccionamos aquellas en las que participaban personas mayores, en general mujeres de edad superior a los 40 años, que habían preparado, o aun preparaban, panchón en la forma tradicional en sus 


\section{perifèria}

Número 7, Diciembre 2007

www.periferia.name

casas. También consideramos otras entrevistas de mujeres y hombres, que lo habían visto hacer, si bien éstos no tienen, en su mayor parte, una visión secuencial e individualizada de cada uno de los pasos del proceso. Realizamos grabaciones digitales de una parte de las entrevistas, siempre con el consentimiento de los entrevistados, y multitud de fotografías relacionadas con la escanda, los aperos empleados en su cultivo, la molienda, y sobre todo de la elaboración del panchón. La trascripción de la variedad dialectal del idioma asturiano empleado por los informantes, se realiza entre paréntesis y en cursiva al lado de la palabra en castellano.

\section{Resultados y discusión}

\section{El ciclo agrario de la escanda}

El cultivo de la escanda es un conjunto de tareas pasadas, laboriosas y tediosas. Se realiza en pequeñas superficies, porque los cultivos en grandes extensiones de terreno, son incompatibles con la lentitud de su recolección tradicional, y con lo complejo de la trilla, que obliga al necesario desergado o descascarillado del grano.

La siembra comienza en noviembre y se puede extender hasta el mes de marzo. Tradicionalmente se realizaba en tierras pobres, pedregosas y poco profundas, y en las laderas de las montañas. El cereal está adaptado a estas condiciones extremas, porque presenta un amplio rango en cuanto a sus requerimientos ecológicos.

La escanda no quier tierra bueno, quier tierra escaso, probe y cuesto. ${ }^{3}$

Las tierras más fértiles se destinaban al maíz, a las patatas, y como pastizales para el ganado. Hoy día se siembra en tierras más fértiles, logrando mejores cosechas en tiempos de cultivo más cortos, de hay que se extienda la siembra hasta el mes de marzo (Rodríguez Gutiérrez, F., 1998-99:62; Farpón Álvarez, F., comunicación oral).

El método de siembra es a voleo, para pasar a continuación la grada, el grade, enterrando la semilla; cuando ésta germine, se entresaca el exceso de plántulas.

\footnotetext{
${ }^{3}$ Teresa Miranda González, Santibáñez de la Fuente, 69 años.
} 


\section{perifèria}

Número 7, Diciembre 2007

www.periferia.name

La simiente utilizada en la siembra es la propia de la casa, la heredada de los antiguos.

A la hora de sembrar hay la costumbre de mirar al cielo y ver hacia donde se mueven las nubes, para comprobar la dirección del viento, pues el del norte trae lluvia y el del sur, calor.

Cuando las nubes van p'al puerto, coge el arado y ponte a techo.

Cuando las nubes van p'al mar, coge el arado y ponte a $\operatorname{arar}^{4}$.

Junto con la semilla de escanda, es tradicional sembrar habas negras, fabes prietes (Vicia faba), que hacen de tutor, ayudando al tallo de la escanda a permanecer erguido. Es una de las formas tradicionales de evitar uno de los mayores problemas de la escanda, el encamado, o caída de la planta al húmedo suelo como consecuencia del viento, de la lluvia, o de un crecimiento acelerado por un excesivo aporte nitrogenado (abonado o cuchado) al terreno. Nos dieron otras explicaciones al empleo de las fabes prietes. Así, en Casomera, se siembran para dar color oscuro a la harina de escanda; esta "atrapa" el color negro de las habas y lo expresaría en el pan. En la localidad de Santo Tomás, en el valle del río Cervigao, siembran les fabes para atraer hacia ellas un virus que si no atacaría a la escanda ${ }^{5}$. Seguramente se refieren a los pulgones negros (Aphis fabae), que parasitan específicamente a la leguminosa en los ápices. Esta alubia es poco apreciada por su dureza cuando está madura, destinándose, salvo en épocas de hambruna, a la alimentación del ganado.

En abril o mayo se eliminan las malezas del cultivo, sayar, y en junio se junta la tierra en torno a los tallos salientes, arriendar.

Quien no sayase el pan en abril a ratos furtaos, sáyalo en mayo a dientes arregañaos ${ }^{6}$.

\footnotetext{
${ }^{4}$ Faustino Riesgo Cordero, Moreda, 41 años.

${ }^{5}$ Senén Vázquez, Santo Tomás, 70 años.

${ }^{6}$ Rosario Cordero García, OMEO, 77 años.
} 


\section{perifèria}

Número 7, Diciembre 2007

www.periferia.name

En junio, por San Juan, San Xuan, a la vez que se celebraba esa mágica noche, se saltaba la hoguera, foguera, y se tomaba la flor del agua, los mozos y mozas tenían la costumbre de colocar un muñeco con forma de mujer, la muyerona, en aquellas tierras de pan que no estuviesen desprovista de maleza y arrendadas.

Poníente la muyerona. Ye un espantexu fechu con un forquitu, con un mandil de muyer y unos palos de brazu?

Entre la maleza que se quita está la carrigüela o corrigüela (Convolvulus arvensis), que estrangula la planta al comenzar a crecer; la meruxa, miruxa (Stellaria media); la visiriga, que aún no hemos podido colectar para determinar de qué especie vegetal se trata; la paniega (Rumex sp.); la hierba porrera (Arrhenatherum elatius subsp. bulbosum); y otras. A las malas hierbas en Aller, en sentido amplio, se las denomina mazacoral o mestranco.

La escanda se recolecta en agosto, o en septiembre, generalmente después de finalizada la siega y recogido el heno, la yerba, mediante una técnica que es considerada singular y propia de Asturias (Alvargonzález, C., 1908: 36.), si bien, algunos etnógrafos han constatado que se realiza de manera similar en el norte del Magreb. Se hace siempre en grupo, a endecha ${ }^{8}$. Hombres y mujeres van provistos de dos palos, de unos $50 \mathrm{~cm}$. de longitud y unos $2 \mathrm{~cm}$. de grosor, unidos en un extremo por un cordel o cinta de cuero para que no se separen; estos aperos, preseos, se llaman les mesories. A modo de horquilla, se colocan las mesorias en la base de las espigas de varios tallos a la vez, (acostumbran a pisar los tallos para no desenraizar la planta), y se tira de de ellas hacia arriba, arrancando las espigas de escanda que se van depositando en un cesto grande (macona, maniega).

Yo no voy a endecha porque non tengo mesories, préstame nena les tuyes y coyeremos a soles ${ }^{9}$.

\footnotetext{
7 Gloria García Solís, Casomera, 71 años.

${ }^{8}$ Andecha. Realizar un trabajo de forma gratuita a favor de un vecino.

${ }^{9}$ Consuelo García González, San Miguel, Nembra, 78 años.
} 


\section{perifèria}

Número 7, Diciembre 2007

www.periferia.name

Apelucar, es otro método de recolección de la escanda. Consiste en cogerla manualmente, espiga a espiga. Esta labor tan tediosa sólo se realiza en caso de encamado y para las espigas que quedaron atrás. Ya que siempre que se cosecha la escanda, detrás de los recolectores, van mujeres y niños cogiendo las espigas dejadas por los segadores y las segadoras. Se dice que los niños inteligentes y trabajadores apelucan o pelucan bien. Así, el término, apeluqueu, servía en el Aller tradicional para adjetivar a un niño, nenu, nino, ninu, que era ordenado, aprovechado, que no dilapidaba nada. El hijo ejemplar (Fernández García, J., 2002 a: 184; García González de Lena, G., 2005: 34).

¡Qué rapaz más mandeu y más apeluqueu, tienes! ¡Da gusto!

Una vez que la macona está llena, el contenido se deposita sobre un sébanu, o sábanu; se trata de un lienzo grande de lino, cerro o cirro, (Linum usitatissimum) que se llena de escanda y se cierra anudando sus extremos. La paja queda en la tierra, para ser más tarde segada. Se utiliza como forraje o como cama para el ganado, pa mullir.

El sábanu se lleva al hórreo, horro u horru, y las espigas permanecen en él unas semanas secando. A continuación se mayan para desproveer a las espigas de sus aristas, arestes, y romper las espigas. Es una forma de trillar característica de este concejo y se diferencia de como se realiza en otras localidades de la montaña central asturiana. Existen dos variantes principales:

- Bailar la escanda o Pisaza ${ }^{10}$. Se pisan las espigas calzando unos zuecos de madera o madreñas, como si se bailase y danzase sobre ellas.

- Golpear las espigas con una especie de mazo, mayu o meyu, con el mango hecho de un palo largo, y que tiene una de sus caras llena de estrías, lo que hace que al golpear la erga se suelte de las espigas, y no salte. En otras zonas, como Omeo, o Llanos, el mayo, consiste en una tabla de superficie rayada, sujeta por un palo, a la que se denomina pisón.

\footnotetext{
${ }^{10}$ Benjamín Lobo Castañón, Conforcos, 85 años.
} 


\section{perifèria}

Número 7, Diciembre 2007

www.periferia.name

El resultado es un grupo de unos tres granos de escanda, erga, provistos aún de sus cubiertas: glumas. La erga se almacena en el hórreo y luego se va llevando a rabilar y moler, a medida que se hace necesario disponer de harina con la que amasar una nueva hornada.

\section{Rabiles y Molinos}

Si un carácter define la rusticidad de la escanda, es el de disponer del grano vestido, es decir, granos protegidos por las envolturas florales, de modo que no se desprenden durante el trillado. Para lograr disponer del grano limpio (escanda como se denomina en Aller), es necesario llevar la erga al rabil, pisón, molino o máquina de rabilar o de desergar.

Los rabiles son de dos clases:

- Manuales. Movidos mediante dos manivelas o rabiles por la fuerza de dos hombres. Apenas queda alguno en el concejo.

- Hidráulicos. Movidos por la fuerza del agua proveniente del río.

Las muelas del rabil son de piedra arenisca, con forma circular, y presentan como característica diferencial de las muelas de molino harinero, la presencia de un picado radial muy profundo, que permite el descascarillado del grano sin que se triture.

Molinos de rabilar movidos por la fuerza del agua había en todo el concejo de Aller. En el catastro del Marqués de la Ensenada, año 1.752, se citan un total de 117, junto con 130 molinos harineros. Un siglo más tarde, el número de molinos había descendido a cien (Fernández García, J., 2002 a: 151, 161). Hay que considerar que en este siglo, se inicia la especialización del campo asturiano hacia la cría de ganado bovino, con el consiguiente cambio en el uso del espacio agrícola: de tierra de pan a prado, para la obtención de forraje.

Al día de hoy, tan sólo funcionan dos molinos en el concejo de Aller. Uno en L'Enfistiella, Nembra. Consta de un rabil y de un molino harinero, movidos por las aguas del río Negro (ríu Nigru). El otro molino está en Conforcos y es eléctrico. Dispone de un rabil y de un molino harinero. 


\section{perifèria}

Número 7, Diciembre 2007

www.periferia.name

El resultado del rabilado hay que limpiarlo: separar el grano de los restos de sus cubiertas, o poxa. Para ello, las mujeres proceden a vanarlo, operación que consiste en aventar el rabilado para separar el grano o escanda de la poxa, por medio de un cedazo de madera llamado vanu o venu, que tiene un fondo de cuero hecho con piel de cordero, de cabrito o de perro ${ }^{11}$ (Dantín Cereceda, J. 1941: 748). La escanda se va llevando al molino para convertirla en harina, farina, a medida que se necesita. Esta harina hay que tamizarla (penerarla o piñerarla), con la penera o piñera. Ésta es un cedazo, cuyo fondo está formado por una malla muy fina, que deja la harina libre del salvado (salvao), que sirve de alimento a gallinas y vacas. Esta harina tan fina es la flor de la escanda; pero cuando no se retira el salvado, a la farina se la denomina mesto, y también se puede amasar pan con ella.

\section{Mantega del Puertu}

La leche, tsechi, tsiche, lleche, llechi, después de ordeñada la vaca, catar o mecer, se dejaba enfriar en una fuente o en un lugar resguardado y frío, esfrecer, para lograr la separación natural de la nata de la leche.

Al día siguiente se colocaba en un odre, piel de cabrito o de oveja, pelada y cosida a modo de recipiente, donde se batía de forma rítmica, mazar, hasta obtener la separación definitiva de la manteca, lo que se sabía por el ruido característico que produce.

Mázate mi tsiche n' esti odre de castrón,

faite muncha mantega y poco requesón ${ }^{12}$.

A la vez que se ordeñaba, o al echar la leche, en la boca del odre se colocaba un curioso filtro para impedir la entrada de suciedad $y$, especialmente, pelos. Dependiendo del pueblo de procedencia del informante, recibe distintos nombres, sin que nos atrevamos a mencionar uno como el más común. Ya que hay una

\footnotetext{
${ }^{11}$ Benjamín Lobo Castañón, Conforcos, 85 años.

12 Pilar Alonso Fernández. Felechosa, 62 años.
} 


\section{perifèria}

Número 7, Diciembre 2007

www.periferia.name

pequeña publicación al respecto de este primitivo y milenario embudo con filtro, de una zona concreta del Concejo donde recibe el nombre de seal, con ese nombre nos referiremos a él (Castañón Caso, A., J. A. de la Pienda, 2005). Se trata de mango de madera, el turnu, al que en uno de sus extremos se ha añadido, en redondo, un conjunto crines o cerdas de la cola de caballo, o de vaca, sedes. Este tamiz, se colocaba en la boca del odre, o dentro de un embudo, por donde se hace pasar la leche. El embudo puede ser de cuerno de vaca cortado por sus extremos, la cuerna, o más elaborado, confeccionado en madera.

Durante su estancia en los pastizales de los puertos, brañas y mayeos, el vaquero bajaba de las cabañas, cabanas, una vez a la semana, a su casa para coger ropa limpia y comida, a la vez que dejaba las mantecas, que eran rápidamente vendidas a intermediarios, la manteguera, que se la revendían en los mercados y a las confiterías.

Excepcionalmente se consumía en la familia, en el caso de mujeres embarazadas, o de niños con un desarrollo menor al esperado, enfermizos y enclenques. De ahí la importancia que tenía el poder disponer de una cierta cantidad de manteca, para la confección del panchón.

En los días de fiesta no se escatimaban gastos, siendo un signo de posición social la cantidad de manteca que este postre contuviese. Añadir una buena cantidad de manteca en el panchón, significaba que la familia estaba en buena posición económica y podía prescindir de la venta de ese producto, para ofrecérselo a la familia.

\section{Elaboración del panchón}

El panchón es un postre que se elabora en las casas del concejo para celebrar algunos días especiales, generalmente las fiestas religiosas locales. Son fechas en las que se reúne la familia, la cercana y la lejana, y tras el almuerzo festivo, se comparte el panchón. Hoy, el panchón se ha convertido en un atractivo gastronómico de las principales villas del concejo, como es el caso de Moreda y su fiesta de San Martín, Ilamada fiesta de Los Humanitarios, del 11 de noviembre. El menú ese día consiste en fabada, casadielles y panchón. 


\section{perifèria}

Número 7, Diciembre 2007

www.periferia.name

El día de San Martín en Moreda,

donde no hay panchón

todos riñen y todos llevan razón.

Este afamado dicho hace referencia, a que cuando no hay comida suficiente, surgen lo problemas y los enfrentamientos.

La elaboración del panchón comienza encendiendo fuego en el hogar, tsar, durante cinco o seis horas. La mejor leña, por unanimidad, es la de haya, faya (Fagus sylvatica), pues quema sin producir humo, despacio, y liberando mucho calor. Pero no se desprecia ningún tipo de madera. En general, se prefiere evitar la madera del castaño (Castanea sativa) pues produce mucho humo. La del fresno, frenu, (Fraxinus excelsior) tiene tan buena consideración como la de faya.

$$
\begin{aligned}
& \text { El fresno a la faya dixo-y } \\
& \text { si no fuera por vergüenza } \\
& \text { ardería bajo el agua. }
\end{aligned}
$$

Mientras roxa el Ilar se va preparando la masa. Se añade un poco de levadura, formientu ${ }^{13}$ o dieldu, sal, y agua (ésta ha de estar bien caliente). Se amasa y se deja fermentar, deldar o dieldar, la masa, pancha, durante una o dos horas, manteniéndola bien tapada con sábanas y mantas.

Transcurrido ese tiempo, si el tsar ya roxó (alcanzó la temperatura propicia), se quitan las cenizas y se reservan las brasas, caricós, se barre bien todo el hogar con una escoba, y se colocan hojas de berza (Brassica oleracea var. oleracea) cubriendo la piedra. Sobre esas hojas se coloca la masa de pan. Se cubre con más hojas de berza, o de arce blanco, plenu o plábanu (Acer pseudoplatanus). La siguiente capa vegetal es de hojas de castaño (Castanea sativa).

\footnotetext{
${ }^{13}$ En aquellos casos en los que se utiliza levadura, llamada aquí formientu, es el propio de la familia, conservado de generación en generación, mediante la extracción de un poco de la masa madre, ya fermentada, deldada o dieldada. Se mete en una taza y se hecha sal por encima, se guarda tapada una hoja de berza (Brassica oleracea L. subsp. oleracea) en la masera. Hoy día se conserva en la nevera. La tendencia actual es utilizar levadura industrial adquirida en una panadería.
} 


\section{perifèria}

Número 7, Diciembre 2007

www.periferia.name

Estos abrigos de hojas son necesarios para aislar la masa de los dos focos de calor, e impedir que se manche con ceniza. Algunos informantes indicaron que las cubiertas de hojas son muy útiles, pues limitan la formación de corteza en el panchón, ya que el resultado que se espera es la obtención de una miga muy compacta, y poca corteza.

Sobre las hojas de castaño se coloca ceniza fría y encima paja, o hierba sobrante del pesebre, piselbe, de las vacas, el llamado retezu. Luego se añade "grana de hierba", o virutas de la madera, urdina, y por último, la capa final la constituyen las brasas ardientes, caricós, que se habían guardado apartadas después de roxar el tsar.

Las llamas que pudieran surgir se apagan, y se deja que la masa vaya cociendo despacio, por espacio de seis a siete horas.

Para comprobar el estado de la cocción, se levantan en un extremo las cubiertas, se da un ligero golpe en la parte despejada, si retumba es que el panchón ya está hecho.

Se retira la masa del lar, se limpia bien de los restos de las cubiertas vegetales, raspando la envuelta con un cuchillo. Este estuante pan se deshace o desmiga, esmigayar, en caliente, pues en frío cuesta más.

En una cazuela se mezclan bien las migas con manteca, bien sea fresca o cocida, y se añade azúcar. Se revuelve bien a fuego lento y tras unos minutos, ya está listo par comer o guardar.

\section{Pan, Borona y Panchón}

En su mayor parte, la cultura del pan asturiana es de influencia romana. La etimología de los nombres dados a los aperos de labranza, el calendario agrícola, los métodos de siembra y recolección, y la división del especio agrario son romanos. Incluso el origen de algunas tradiciones como es la de bendecir las tierras el día de Ramos, con una rama de laurel (Laurus nobilis) y agua bendita, a la vez que se pronuncia una jaculatoria, y se clava, al finalizar, el laurel en la tierra, es romana (Alvargonzález, C., 1908: 6, 21, 33; Martínez Lorenzo, L., 2002). 


\section{perifèria}

Número 7, Diciembre 2007

www.periferia.name

A fuyir mures y toda la comición, que eí os va el agua de la bendición ${ }^{14}$.

Pero evidencias arqueopalinológicas, etnográficas, lingüísticas e históricas, permiten deducir, que el inicio de la tradición cerealista asturiana es prerromana, y ambas, prerromana y romana, han coexistido hasta nuestros días.

Una de estas formas de coexistencia hace referencia a los distintos métodos de cocción del pan: una primitiva, prerromana, sobre piedras previamente calentadas; y otra, de procedencia romana, en un horno calentado, roxao, con leña. El resultado final en uno y otro caso también es distinto, y también es distinto el cereal empleado. En el lar se cuece una masa hecha con harina de maíz, y se obtienen tortas, tortos y boronas o boroñas; en el horno, la masa es de harina de trigo, de centeno, o de escanda, para obtener multitud de panes, bollos preñaos, empanadas, pegarates, etc.

Pero no en todos los casos es así. Uno de los productos elaborados con harina de escanda, el pan por derecho propio en la zona centro y oriente de Asturias, va a ser el resultado de la cocción sobre un lar y no en un horno. Estamos hablando del panchón allerano. Esta es una de sus características culturales: entronca directamente con una cultura del pan milenaria.

\section{I mportancia social del panchón}

Para comprender la importancia del panchón, hay que adentrarse en una organización social que desaparece; en la vida rural enmarcada en unos ritmos de trabajo que llenaba jornadas enteras de fatigas y esfuerzos enormes.

De los productos que integran el panchón, solo el pan, y cocido en horno, estaba presente en el almuerzo (xinta) diario. La manteca, que se producía en la unidad familiar, era destinada a la venta y no para el autoconsumo, salvo en muy contadas ocasiones; el azúcar, tenía un precio que la familia campesina no se podía permitir, siendo la miel el edulcorante habitual.

\footnotetext{
14 iHuir ratones y plagas del campo, que hay os va el agua de la bendición!. Comición no tiene traducción directa al castellano, hace referencia a cualquier plaga, especialmente animal, que come lo sembrado.
} 


\section{perifèria}

Número 7, Diciembre 2007

www.periferia.name

La dieta diaria era monótona y escasa. Los pocos momentos para el descanso, los días del patrón o la patrona local, introducían rasgos diferenciadores del día a día. Las comidas del día de fiesta se alejaban de la penuria diaria, eran pantagruélicas. Principal y básicamente aparecían las carnes, que durante el resto del año apenas se probaban, en todas sus formas, variedades y sabores: pollos, gallinas, cerdo, vaca... Se comía hasta no poder más, y como remate, final de un día en el que se saciaban un poco, nunca del todo, las hambres, el panchón (Fernández García, J., 2004).

\section{Conclusiones}

- La escanda es un cereal panificable de una gran importancia en la cultura rural asturiana, cuyo cultivo se considera relicto.

- La forma de recolección de la escanda, utilizando dos palos unidos por una corta cuerda, a modo de tijera, es única en el conjunto de las técnicas agrícolas tradicionales que practican o practicaron los pueblos de la Península Ibérica.

- La forma de cocción de la masa de pan o pancha, de la que se extrae el panchón, entronca directamente con tibios restos de una cultura del pan anterior a la llegada de los romanos al norte peninsular.

- Los ingredientes del panchón, aparentemente modestos, definen perfectamente la sociedad rural y ganadera de la que proceden.

\section{Bibliografía}

Arias Cabal, A. (1995). "El pan y el panchón en Felechosa (Ayer)", Cultures, 5: 108.

Asociación de Mujeres Campesinas de Asturias (2003). Sabores y saberes de las mujeres rurales asturianas. Oviedo: Ed. Novel.

Baranda ", Tecnología Agroalimentaria. Boletín Informativo del SERIDA. Villaviciosa, 1: 41-45.

Castañón Caso, A., J. Avelino de la Pienda (2005). "El seal, un colador milenario", Magíster: Revista miscelánea de investigación. Universidad de Oviedo.

Concepción Suárez, Julio (2004). "La alimentación en la casa del monte y en las brañas de la montaña central asturiana", Etnografía y Folklore asturiano. Cursos 2001/2002 y 2002/2003. Oviedo: Real Instituto de Estudios Asturianos. 159-194. 


\section{perifèria}

Número 7, Diciembre 2007

www.periferia.name

Conceyu d'Estudios Etnográficos Belenos (1998). Asturies. Memoria Celta. Fundación Belenos. Uviedu.

Dantín Cereceda, J. (1941). "Distribución geográfica de la escanda asturiana", Estudios Geográficos, 5: 739-797.

Eslava Galán, Juan (2002). Historia de España contada par escépticos. Barcelona.

Exposición pan de escanda. Concejo de Quiros.

<http://www.vivirasturias.com/texto/ficha/exposicion-de-pan-de-escanda-4166441987.html> [Consulta: 20-02-2006].

Fernández Benítez, Vicente... et al. (2002). Trabayar pa comer. Producción y alimentación na Asturies tradicional. T. I.: Documentación xeneral. Fundación Municipal de Cultura, Educación y Universidá Popular, Conceyu de Xixón.

Fernández García, Joaquín (2002a). "La vida tradicional en el concejo de Aller", Etnografía y folklore asturiano: Conferencias 1998-2001. Real Instituto de Estudios Asturianos. Oviedo: 137-197.

Fernández García, Joaquín (2002 b). "La vida tradicional de Aller en su poesía popular", Etnografía y folklore asturiano: Conferencias 1998-2001. Real Instituto de Estudios Asturianos. Oviedo: 137-197.

Fernández García, J. (2002 c). Moreda y sus habitantes en la poesía popular allerana. Pregón a las fiestas de San Martín, Moreda de Aller, 11 de noviembre de 2002.

Fernández García, J. (2004). Comer para trabajar y sobrevivir. (La alimentación tradicional en el concejo de Aller). Apuntes de la Conferencia celebrada en el Real Instituto de Estudios Asturianos. Oviedo. En prensa.

Fernández Lamuño, Julio A. (1998). Cultivos tradicionales e Industrias rurales en el Occidente Asturiano. Imprenta Nonaya, Salas.

Fernández Riestra, F. \& M. González Fernández (2003). Delles notes alrodiu de los marcos de pan n'Asturies. Asturias. Memoria encesa d'un país

Ferreira Fernández, J. J., G. García González de Lena (2005). "Actuaciones del 


\section{perifèria}

Número 7, Diciembre 2007

www.periferia.name

SERIDA para la mejora de la producción de escanda", Tecnología Agroalimentaria. Boletín Informativo del SERIDA. Villaviciosa, 1: 35-39.

García González de Lena, G. (2005). "La escanda, un poco de historia", Tecnología Agroalimentaria. Boletín Informativo del SERIDA. Villaviciosa, 1: 28-29.

García González de Lena, G. (2005). "El cultivo de la escanda en Asturias", Tecnología Agroalimentaria. Boletín Informativo del SERIDA. Villaviciosa, 1: 30-34.

García González de Lena, G. (2005). "El futuro de la escanda en Asturias", Tecnología Agroalimentaria. Boletín Informativo del SERIDA. Villaviciosa, 1: 39-40.

García Lado, M. A. (2004). Retazos de la Artesanía Popular Asturiana. Tomás Badiola (ed.)

González, José Manuel (1976). Antiguos pobladores de Asturias (Protohistoria). Ayalga ediciones. Salinas (Asturias).

González-Quevedo González, R. (2002). Antropología Social y Cultural de Asturias: Introducción a la Cultura Asturiana. Madu Ediciones. Granda (Siero).

González-Quevedo González, R. (1995). "El pan astur", Cultures. Revista asturiana de cultura. Oviedo, 5: 9-35.

Hancock, James F. (2004). Plant Evolution and the Origin of Crop Species. Cambridge, MA, USA: 190-194.

López Álvarez, Xuacu (1994). Las abejas, la miel y la cera en la sociedad tradicional asturiana. Real Instituto de Estudios Asturianos. Oviedo.

Martínez González, J., J. J. Lastra Menéndez (2006). Ethnobotanical study of the cattle farmers profile in the Aller Valley (Asturias, Spain). EN: Proceedings of the Fourth International Congress of Ethnobotany (ICEB 2005). Ege Yayinlari, Istanbul.

Martínez González, J., J. J. Lastra Menéndez, J. J. (2007). El panchón en el concejo de Haller. Real Instituto de Estudios Asturianos (en prensa).

Oliveira Prendes, J. A. (2001). "North Spanish emmer and spelt wheat landraces: agronomical and grain quality characteristic evaluation", Plant Genetic Resources 


\section{perifèria}

Número 7, Diciembre 2007

www.periferia.name

Newsletter, 125: 16-20.

Oliveira Prendes, J. A. (2004-2005). "Comportamiento agronómico y calidad harinopanadera de dos variedades locales de escanda en Carreño (Asturias)", Bol. Cien. Nat. R.I.D.E.A., 49: 67-75.

Pérez Pinto, J. E., M. J. Zamora Fernández (1992). Recorrido paisajístico por el Concejo de Aller. Servicio de Publicaciones del Principado de Asturias. Mieres.

Rodríguez-Castellano, Lorenzo (1986). La variedad dialectal del Alto Aller. Ed. Facsimilar de la de 1952. Instituto de Estudios Asturianos. Oviedo.

Rodríguez Gutiérrez, Fermín (1998-99). Proyecto de recuperación del cultivo de la escanda en clave de desarrollo local, en los concejos de Aller, Lena y Quirós. Cámara de Comercio, Industria y Navegación de Oviedo.

Rodríguez Hevia, Vicente (2001). "Rabiles y molinos nel Conceyu Llaviana", Asturias. Memoria encesa d'un país. 12: 62-76

Tarrazo, Pilar (2002). El Escaldao. Viejo Cubia: Revista historico-cultural de Grado, 1 (http://viejocubia.grao.net/))

Zohary, D. and M. Hopf (2000). Domestication of plants in the old World. The origin and spread of cultivated plants in West Asia, Europe and the Nile Villey. Oxford University Press. New York 